Published in Social Science Quarterly 95(3):701-718.

https://onlinelibrary.wiley.com/doi/pdf/10.1111/ssqu.12085

\title{
Politics, Religion, Attribution Theory, and Attitudes toward Same-Sex Unions
}

\author{
Andrew L. Whitehead \\ Clemson University
}

Objective: The relationship between beliefs about the cause of homosexuality, political and religious ideology, and attitudes toward same-sex unions in the United States is unclear. This study aims to examine the mediating influence and socially embedded nature of attribution beliefs at a time when attitudes toward same-sex unions are undergoing substantial changes in the American public.

Method: This study employs simultaneous equation path models and a recent national, random sample of American adults (Baylor Religion Survey 2010) to test each hypothesis.

Results: Results reveal that constructed opinions about the origin and controllability of homosexuality significantly influence support for same-sex unions. However, these opinions are socially embedded, especially within particular political and religious ideologies.

Conclusion: These findings highlight that while widespread changes in beliefs about the cause of homosexuality may presage shifts in support for same-sex unions, many will be able to resist those shifts toward support, possibly leading to their further marginalization within society. 
Recent research reveals that attitudes toward same-sex unions are influenced by a number of sources. Predictably, political views and religious beliefs are powerful predictors of an individuals' view of same-sex unions (Sherkat et al. 2011). However, a growing number of studies suggest that how individuals perceive the cause of homosexuality is an important mediator of political and religious influences (Haider-Markel and Joslyn 2008; Whitehead 2010; Wood and Bartkowski 2004). First, political views and religious beliefs influence individuals' attribution of the cause of homosexuality. Then, in separate models, those attributions influence individuals' views toward same-sex unions even when controlling for political and religious influences. While the association between politics, religion, and same-sex unions never disappears, it is reduced with the inclusion of attribution beliefs. Furthermore, attribution beliefs are the strongest predictors in the model. This suggests that political and religious beliefs influence the attribution beliefs individuals maintain, which then sway their views toward same-sex unions. However, none of the studies examining attribution beliefs and same-sex union attitudes have tested this proposed relationship. The present analysis provides such a test. Using a recent, national survey of American adults and simultaneous equation path analysis, this study advances the current literature on attitudes toward same-sex unions and attribution theory. The importance of attribution beliefs finds strong support. Shifts in these beliefs will affect attitudes toward same-sex unions. However, these analyses also demonstrate that attribution beliefs are socially embedded. Therefore, despite changes in someone's attribution beliefs, or evidence that might make certain attribution beliefs untenable, attitudes toward same-sex unions could remain stable. Religion, Politics, and Attitudes toward Same-Sex Unions

Recent literature on the relationship between religion and attitudes toward homosexuality focuses specifically on the right of lesbians and gays to marry or obtain civil unions. It highlights religious belief, behavior, and affiliation as important predictors of an individuals' level of acceptance of same-sex rights. Religious belief, such as a literal view of the Bible, is associated with nonapproving stances regarding same-sex rights (Sherkat et al. 2011; Whitehead 2010). Biblical literalism 
is always one of the most powerful predictors of attitudes toward same-sex unions. Individuals who frequently attend religious services or who consistently engage in private religious devotions such as prayer or scripture reading are less likely to be favorable toward same-sex unions (Haider-Markel and Joslyn 2008; Olson et al. 2006). Finally, Evangelical and Black Protestant denominations are less accepting of same-sex marriage or civil unions than Mainline Protestants, Jews, and the unaffiliated (Olson et al. 2006; Sherkat, de Vries, and Creek 2010). In general, religious conservatism is consistently associated with various attitudes toward lesbians and gays and their civil rights.

Political views and affiliations are robustly associated with attitudes toward same-sex unions. Individuals who identify as politically liberal are time and again more favorable toward gays and lesbians having the right to marry or obtain civil unions (Haider-Markel and Joslyn 2008; Sherkat et al. 2011). Conversely, more conservative political views associate with less support for same-sex unions. Net of a variety of other effects, political conservatism is one of the most prominent predictors of attitudes toward same-sex unions.

Attribution Theory and Attitudes toward Same-Sex Unions

Perceptions of the cause of homosexuality are crucial when predicting attitudes toward samesex civil rights. Central to this argument is whether or not gays and lesbians can "control" their orientation. Attribution theory was first proposed by Austrian psychologist Fritz Heider (1944; 1958). He theorized that individuals seek to explain the behaviors of those around them in an attempt to predict and control their environment by attributing others' behavior to either internal or external causes. Weiner $(1979 ; 1985)$ furthered attribution theory by emphasizing the concept of controllability. When certain behaviors are labeled "controllable" the person exhibiting the behavior can be held responsible while behaviors labeled "uncontrollable" mean the person exhibiting the behavior is less likely to be held accountable. If the behavior in question is stigmatized in some way and considered controllable, those exhibiting the behavior are much more likely to be viewed negatively. A number of studies find support for attribution theory when investigating attitudes toward 
poverty (Griffin and Oheneba-Sakyi 1993; Zucker and Weiner 1993), obesity (Crocker, Cornwell, and Major 1993), and when comparing stigmas commonly classified as uncontrollable (Alzheimer's) versus controllable (AIDS) (Weiner, Perry, and Magnusson 1988).

Studies investigating attitudes toward gays and lesbians provide additional support for attribution theory (Herek 2002; Herek and Capitanio 1995; Sakalli 2002). Individuals who attribute homosexuality to a source outside personal control are more likely to hold favorable views of lesbians and gays while individuals who believe lesbians and gays choose their orientation are less likely to be favorable. Some researchers suggest that an individual's belief about the cause of homosexuality is the single most important predictor of attitudes toward gays and lesbians (Herek and Capitanio 1995:95). Recent work investigating attitudes toward same-sex unions continues to apply attribution theory. Support for same-sex marriage and civil unions is much more likely if homosexuality is believed to be the result of natural or biological forces outside the individuals' locus of control (Haider-Markel and Joslyn 2008; Wood and Bartkowski 2004). Conversely, support for same-sex unions is less likely if individuals believe homosexuality is the result of a choice (Whitehead 2010; Wood and Bartkowski 2004). In each of these studies individuals' attribution beliefs are the strongest predictors of attitudes toward same-sex unions even while controlling for demographic, political, and religion measures. Religion, Politics, and Attributions of the Cause of Homosexuality

Due to the power of attribution beliefs, researchers investigated who is most likely to view homosexuality as a choice or due to natural forces. Haider-Markel and Joslyn (2008) found that religious behavior and affiliation are associated with the belief that homosexuality is the result of genetics. Evangelical Protestants are much less likely to believe genetics influence sexual orientation as are those who attend religious services at higher rates. Their analysis showed that political conservatism likewise predicts an aversion toward biological explanations of homosexuality. Focusing instead on who is more likely to believe gays and lesbians choose their sexual orientation, one study found that biblical literalism was associated with attribution beliefs along with religious behavior and 
affiliation (Whitehead 2010). Evangelical Protestants were most likely to believe that homosexuality is the result of a choice compared to other religious traditions and individuals who attend religious services at higher rates were more likely to believe lesbians and gays choose their orientation. Regarding political views, individuals who identify as politically conservative were more likely to believe that gays and lesbians choose their sexual orientation. In both of these studies, religious and political conservatism were the most robust predictors of particular attribution views.

Toward a Structural Model

Attribution theory and the current literature detailed above imply a particular relationship between attribution beliefs and attitudes toward same-sex unions. The results of past studies demonstrate that religion, politics, and various other predictors are associated with attribution beliefs but also with same-sex union attitudes. This suggests that attribution beliefs may operate as a mediating variable, especially for religious and political conservatism. Attribution theory also proposes this relationship: individuals acquire a particular view of the origin of a stigmatized status and this influences their feelings about the morality or rights of the stigmatized. Again, attribution theory focuses on how individuals attribute the cause of a behavior, such as whether it is internal or external to the person and also whether the individual has any level of control. But from where do the explanations for whether a behavior or status is internal or external, controllable or not, come? As Haider-Markel and Joslyn (2008:307) state, "individuals rely heavily on ideology [and] religion . . to form beliefs." In many cases religious and political ideology function as sources of moral authority that dictate which beliefs are deemed acceptable (Whitehead and Baker 2012). These sources are vital regarding attitudes toward gay rights and beliefs about whether same-sex attraction is due to internal or external factors and is controllable or not. In this case, political and religious conservatism are prior to attribution beliefs. Put another way, attribution beliefs serve as part of the explanation why religious or political beliefs either support or oppose homosexuality.

This leads to the first hypotheses: 
H1a: Attribution beliefs mediate the relationship between political conservatism and attitudes toward same-sex unions.

H1b: Attribution beliefs mediate the relationship between religious conservatism and attitudes toward same-sex unions.

Figure 1 displays these hypothesized relationships. By mediate I refer to the relational sequence between political and religious conservatism leading to particular styles of attribution which collectively produces a particular set of outcomes. Past analyses were unable to formally test this assumption due to methodological limitations. These methodological limitations necessitate a more precise modeling technique to determine if the theorized relationship exists.

[Figure 1 about here]

While past research demonstrates that attribution beliefs are without fail the strongest predictor of same-sex union attitudes, religious and political conservatism, two important predictors of attribution beliefs, also maintain significant and robust associations with attitudes toward same-sex unions even when controlling for attribution beliefs (Haider-Markel and Joslyn 2008; Whitehead 2010). One explanation is that political and religious ideologies are foundational concerning attitudes toward moral issues (Putnam and Campbell 2010; Whitehead and Baker 2012). As discussed above, religious and political sources of moral authority are primary to attribution beliefs. This suggests that the total effect of political conservatism, the sum of its direct effect on same-sex union attitudes and its indirect effect mediated through attribution beliefs, may exceed the direct effect of attribution beliefs on same-sex union attitudes. The same can be said for religious conservatism. Put differently, the foundational influence of political and religious conservatism as sources of moral authority may overshadow the effect of attribution beliefs because these sources of moral authority are vital to the formation of those particular attribution beliefs.

Yet, in past studies, the possible indirect effects of political and religious conservatism on attribution beliefs are left unexamined. This results in only being able to determine their "net" effect. 
Therefore, assessing both direct and indirect effects in simultaneous equations will allow for a more accurate analysis of the relationships between religion, politics, attribution beliefs, and attitudes toward same-sex unions. This leads to a second and third hypothesis:

H2: The total effect of political conservatism will exceed the total effect of attribution beliefs.

H3: The total effect of religious conservatism will exceed the total effect of attribution beliefs. The structure of the interrelationships in figure 1 allow for the testing of each hypothesis.

A number of substantive implications of this analysis deserve mention. If religion or political views prove to have the largest total effect on same-sex union attitudes a growing acceptance of a natural explanation of homosexuality could lead to increased hostility toward gays and lesbians. As Haider-Markel and Joslyn (2008:308) point out, "the next step may not be tolerance but intervention. If the homosexual gene can be altered or manipulated in some way, the notion that homosexuality can be 'cured' will surely be considered." This prediction is supported by the fact that the possibility of a natural explanation for homosexuality tends to only further polarize previously held beliefs (Boysen and Vogel 2007). Boysen and Vogel (2007:755) state that "learning about biological explanations of homosexual behavior is interpreted through the lens of preexisting attitudes." As another study points out, "It is possible that certain views toward attribution are co-opted, in a sense, by . . . individuals to provide supplementary support to their previously held beliefs" (Whitehead 2010:76). Therefore, if direct and indirect effects of religion and politics on attitudes toward same-sex unions are greater than beliefs about the cause of homosexuality, a further polarization of positions could result if the scientific community ever coalesces around a natural explanation. Individuals with certain political or religious beliefs would merely jettison their chosen attribution belief and find novel ways to support and maintain previous stances.

However, if political conservatism and religion exhibit a marginal effect on attribution beliefs and a small total effect on same-sex union attitudes, the increased acceptance of a biological explanation within the scientific community could reframe the entire issue of same-sex unions (Olson 
et al. 2006). This reframing of the issue would lead to greater acceptance of same-sex marriage and civil unions in larger proportions of the population. In this case individuals' attribution beliefs would be at the crux of their support or opposition to same-sex unions.

Data

Data for this study are taken from Wave III of the Baylor Religion Survey (BRS) fielded in 2010 by the Gallup Organization. The BRS is a national random sample of non-institutionalized American adults. The survey utilized a mixed-mode sampling design consisting of two phases. Both phases resulted in a total of 3,500 individuals screened and 2,556 possible respondents. A total of 1,714 questionnaires were returned resulting in a response rate of $49 \%[1,714 / 3,500]$ among all individuals screened and a response rate of $67 \%[1,714 / 2,556]$ for those who agreed to receive a mailed survey. The $2010 \mathrm{BRS}$ is ideal for the existing research question because it is recent and contains a number of questions pertaining to religion, political views, attitudes toward the cause of homosexuality, and support for same-sex unions the combination of which is not found in any other large, national survey. Dependent Variables

The first dependent variable measures respondents' support of same-sex civil unions. The question in the BRS asks, "Please describe how you feel about homosexuality for the following statements: Homosexuals should be allowed civil unions." Possible responses range from "Strongly Agree" to "Strongly Disagree." The second dependent variable asks about same-sex marriage: "Homosexuals should be allowed to legally marry." Possible responses again range from "Strongly Agree" to "Strongly Disagree." Both measures were dichotomized ( 1 = Strongly Agree and Agree). Mediating Variables

The mediating variables relate to respondents' beliefs about the cause of homosexuality. One measures whether individuals believe homosexuality results from natural causes. It asks: "Please describe how you feel about homosexuality for the following statements: People are born either as 
homosexual or heterosexual." Possible responses range from "Strongly Agree" to "Strongly Disagree." The other measure of attribution beliefs asks if sexual orientation is a personal choice: "People choose to be homosexuals." Possible responses again range from "Strongly Agree" to “Strongly Disagree." Both measures were dichotomized ( 1 = Strongly Agree and Agree).

I utilize both measures of attitudes toward same-sex unions and both measures of attribution beliefs available in the BRS (2010) for two reasons. First, past analyses use these as separate variables; including each allows for comparisons between the present study and past work. Second, by utilizing combinations of each dependent and mediating variable I can ensure that the hypothesized relationships between religious and political conservatism, attribution beliefs, and attitudes toward same-sex unions are persistent and not dependent upon the type of attribution belief (nature or choice) or the type of same-sex union (marriage or civil unions) included in the model. Finally, I dichotomize these measures because the substantive difference between supporting versus opposing same-sex unions for each attribution belief is essential, not the differences between agreeing or strongly agreeing. This coding strategy is commonly used in past research on this topic as well (Olson et al. 2006; Sakalli 2002; Sherkat et al. 2010; Sherkat et al. 2011; Whitehead 2010).

[Table 1 about here]

Independent Variables

The independent variables of interest include measures of both political and religious conservatism. The question used to measure political conservatism asks respondents, "How would you describe yourself politically?" Possible responses were "Extremely Liberal," "Liberal," "Leaning Liberal," "Moderate," "Leaning Conservative," "Conservative," and "Extremely Conservative." Higher values correspond to more conservative political views $(1=$ Extremely Liberal to $7=$ Extremely Conservative).

To measure religious conservatism I rely on a measure of religious belief as well as religious affiliation. Regarding religious belief, I utilize a question asking respondents for their view of the 
Bible: "Which one statement comes closest to your personal beliefs about the Bible?" Responses included, "The Bible means exactly what it says. It should be taken literally, word-for-word, on all subjects," "The Bible is perfectly true, but it should not be taken literally, word-for-word. We must interpret its meaning," "The Bible contains some human error," and "The Bible is an ancient book of history and legends." Respondents who answered "I don’t know" were counted as missing. Higher values correspond to more literal views of the Bible and greater religious conservatism. I account for religious affiliation using a typology of religious traditions (Steensland et al. 2000). Categories include Evangelical Protestant, Black Protestant, Mainline Protestant, Catholic, Jewish, Other, and No affiliation. Evangelical Protestant serves as the contrast category. Control Variables

A number of control variables are included in the analyses. Age (in years), race $(1=$ Black), and education $(1=8$ th grade or less to $7=$ Postgraduate work/Degree $)$ were significantly associated with attribution beliefs and same-sex union attitudes in past research and so each measure is allowed to predict both the attribution and same-sex union variables. Gender $(1=$ Female $)$ and religious affiliation were found to have significant associations with attribution beliefs but not same-sex union attitudes in past research once attribution beliefs were included in the model. Therefore, these measures are allowed to predict the attribution measure but not the same-sex union measure. Finally, marital status $(1=$ married $)$ and region $(1=$ South $)$ were found to have significant associations with attitudes toward same-sex unions but not attribution beliefs in prior studies. So, these measures were not allowed to predict attribution beliefs but were permitted to predict same-sex union attitudes.

A final religion measure is included. Religious behavior is determined using religious worship service attendance. The response categories included, "Several times a week," "Weekly," "About weekly," "2-3 times a month," "Once a month," "Several times a year," "Once or twice a year," "Less than once a year," or "Never." Higher values correspond to more frequent worship service attendance $(1=$ Never to $9=$ Several times a week). This measure is allowed to predict both attribution beliefs 
and same-sex union attitudes due to findings in prior research. While it could be argued that religious behavior is a marker of religious conservatism, political ideology and religious conservatism as defined here operate as sources of moral authority and each can be more directly compared to attribution beliefs in how they influence individuals. Frequent attendance, in and of itself, is not a source of moral authority for individuals. It is where they attend and the view of the scriptures common to that group that operate as a source of authority. For this reason, I do not treat religious behavior as a particular marker of religious conservatism to be compared with political conservatism and attribution beliefs. Methodology

Analyses are conducted using Mplus 6.11 to estimate the simultaneous equation path models (Muthén and Muthén 1998-2010). Structural equation and path modeling offer methodological improvements over standard regression techniques by accounting for the interrelationships between all of the exogenous variables as well as assessing their direct, indirect, and joint effects (Schumacker and Lomax 2010). This allows for investigation beyond "net" effects presented in past analyses. The proposed mediating role of attribution beliefs can also be tested. Because both endogenous variables are binary, a robust weighted least square parameter estimator is most appropriate (WLSMV) (Asparouhov \& Muthén 2010). WLSMV uses the diagonal of the weight matrix in the estimation while the standard errors and the mean and variance adjusted chi-square test statistic utilize a full weight matrix (Muthén and Muthén 1998-2010).

I utilize multiple imputation (MI) using Bayesian analysis to correct for missing data (Enders 2010; Schafer 1997). This procedure produced five data sets and parameter estimates were averaged over the set of analyses. The standard errors were computed using the average of the standard errors over the set of analyses and the between analysis parameter estimate variation (Muthén and Muthén 1998-2010; Schafer 1997). In order to test the first hypothesis, I make use of multiple assessments of overall model fit. The chi-square statistic indicates whether the model-implied covariance matrix differs significantly from the observed matrix. A significant chi-square signifies an ill-fitting model. 
Because the chi-square can be influenced by larger sample sizes, I utilize additional fit indicators. Two baseline comparison indices, the Tucker-Lewis index (TLI) and the Comparative Fit Index (CFI), and the root mean square error of approximation (RMSEA) provide further confirmation of model fit. Due to my interest in comparing the total effects across measures I report standardized coefficients. These will allow for evaluations of the final two hypotheses.

Results

Figures 2 through 5 display the results of four simultaneous equation path models. Each model includes one combination of attribution belief and type of same-sex union. Figures 2 and 3 focus upon same-sex marriage. Figure 2 estimates the relationship between believing homosexuality is a choice and same-sex marriage. The structure of the path model fits the data. The chi-square statistic is not significant $(\mathrm{p}=0.822)$. Furthermore, the CFI and TLI are both at or very near their ideal value of 1.0 and the RMSEA is less than .05 suggesting good overall model fit (Jöreskog 1993; Schumacker and Lomax 2010). I find that age and education are negatively associated with believing homosexuality is a choice. Women do not believe sexuality is a choice to the degree that men do. Identifying as black, higher levels of attendance, and biblical literalism are positively associated with believing homosexuality is a choice. Political conservatism is positively associated as well. There are no significant differences between Evangelical Protestants and all other religious traditions including the unaffiliated. Believing homosexuality is a choice is negatively associated with support for same-sex marriage. Age, biblical literalism, political conservatism, and worship service attendance are negatively associated as well. However, higher education is positively associated with support for same-sex marriage.

[Figures 2 and 3 about here]

Figure 3 estimates the relationship between believing sexual orientation is genetic and support for same-sex marriage. The covariance matrix implied by this model structure does not differ significantly from the observed matrix suggesting good overall model fit. The chi-square statistic is not 
significant $(\mathrm{p}=0.615)$ and the CFI, TLI, and RMSEA are all at or very near their ideal values providing additional support. The results show that age is associated with believing sexuality is present at birth. Women tend to believe this more so than men while blacks ascribe to this view less frequently than whites. However, political conservatism, biblical literalism, and worship service attendance are negatively associated with believing homosexuality is the result of genetics. Again, there are no significant differences between Evangelical Protestants and the other religious traditions and the unaffiliated. Believing homosexuality is innate is positively associated with same-sex marriage. Level of education is positively associated with same-sex marriage. Biblical literalism, political conservatism, and age are negatively associated with support for same-sex marriage.

Figures 4 and 5 focus on attitudes toward same-sex civil unions. Figure 4 assesses the relationship between believing homosexuality results from a choice and support of same-sex civil unions. The model fit statistics indicate a good overall fit. The chi-square is not significant $(\mathrm{p}=$ 0.166) and the CFI, TLI, and RMSEA are all near their ideal values. Again we see that age and education are negatively associated with believing homosexuality is a choice. Women are less likely than men to consider homosexuality the result of a choice. Political conservatism, biblical literalism, and religious service attendance are positively associated with believing gays and lesbians choose their orientation. Once more, religious affiliation is not significantly associated with attribution beliefs. Believing homosexuality is a choice is negatively associated with support for same-sex civil unions. Age, being from the south, political conservatism, biblical literalism, and attendance are also negatively associated. Education is positively associated with support for same-sex civil unions.

[Figures 4 and 5 about here]

Figure 5 estimates the relationship between believing homosexuality is genetic and same-sex civil unions. The chi-square statistic is not significant $(\mathrm{p}=0.169)$ and the CFI, TLI, and RMSEA suggest that the model-implied structure is not significantly different from what is found in the data again indicating good overall model fit. Age and gender are positively associated with believing gays 
and lesbians are born with a particular sexual orientation. However, blacks are less likely to ascribe to this view than whites. Biblical literalism, political conservatism, and religious service attendance are all negatively associated with believing homosexuality is innate. Yet again, Evangelical Protestants are not significantly different from any other religious tradition concerning attribution beliefs. Believing homosexuality is innate is strongly and positively associated with support of same-sex civil unions. Education is positively associated while age, political conservatism, and biblical literalism are negatively associated with support for civil unions, as is being from the South.

Due to our interest in the direct, indirect, and total effect sizes rather than just "net" effects, table 1 provides the standardized total effects for the variables of interest: attribution beliefs and political and religious conservatism. The upper portion of the table contains the standardized results from the models examining attitudes toward same-sex marriage with the choice attribution model on the left and the nature attribution model on the right. The bottom portion of the table examines attitudes toward same-sex civil unions with the standardized results from the choice attribution model reported on the left and the standardized results from the nature attribution model reported on the right. While religious conservatism is measured through biblical literalism and religious affiliation, only the standardized results of biblical literalism are displayed because of the non-significance of religious affiliation in all four models. Consistently, across all four models, attribution beliefs have the largest total effect on attitudes toward same-sex unions. Political conservatism exhibits the next largest total effect size across all of the models. Biblical literalism is the third largest in total effect.

[Table 1 about here]

\section{Discussion}

Results from the four simultaneous equation path models provide consistent support for the first hypothesis. Attribution beliefs appear to operate as a mediating variable when examining attitudes toward same-sex unions. The chi-square test statistic is not significant in each model and the CFI, TLI, and RMSEA are all close to their ideal values. This suggests that the hypothesized model 
does not differ significantly from the observed data. While past research was unable to model the mediating role of attribution beliefs, simultaneous equation path analysis offers a more precise test of attribution theory. It appears that individuals acquire a particular view of the origin of a stigmatized status and this influences their feelings about the morality or rights of the stigmatized (Heider 1944, 1958; Weiner 1979, 1985).

In addition to the support for the mediating role of attribution beliefs, the results demonstrate these beliefs exhibit the largest standardized effects across each model. Regardless of whether attribution beliefs are operationalized using the choice or nature measures, or if same-sex marriage or civil unions are being examined, how people define the cause of homosexuality is the strongest predictor of their feelings toward gay rights (Herek and Capitanio 1995). Prior research expressed the importance of attribution beliefs in comparison to other measures, especially political and religious conservatism, but was unable to account for their indirect effects (Haider-Markel and Joslyn 2008; Herek and Capitanio 1995; Whitehead 2010; Wood and Bartkowski 2004). The present analysis reveals that even when accounting for the indirect effects of religious and political conservatism attribution beliefs are still the strongest in the model. This suggests that attribution beliefs are a crucial mechanism through which attitudes toward same-sex unions are constructed. Changes in individuals' attribution beliefs could lead to changes in their level of support for same-sex unions.

Hypotheses 2 and 3, therefore, fail to receive support. The total effects of political conservatism and religious conservatism fail to exceed the total effect of attribution beliefs. While both measures are strongly associated with attribution beliefs and attitudes toward same-sex unions, neither surpasses the total effect of attribution beliefs. Political conservatism comes close to achieving the largest standardized total effect when predicting attitudes toward same-sex marriage with the choice measure as the mediating variable. When comparing the standardized total effects of political and religious conservatism we find that how individuals' identify themselves politically is more 
strongly associated with attitudes toward both attribution beliefs and same-sex unions across all models.

A number of additional findings in line with past research are worth noting. First, higher levels of education result in more favorable views toward same-sex unions and an unwillingness to view homosexuality as a choice. Higher levels of religious service attendance have the opposite effect. Interestingly, age has countervailing effects. Older adults favor the idea that homosexuality is innate rather than a choice, but also tend to oppose same-sex marriage and civil unions. Overall, increasing age has a negative association with attitudes toward same-sex unions. In line with previous research, women are more likely to view homosexuality as innate rather than a choice. Past analyses show that when controlling for attribution beliefs gender is not significantly associated with attitudes toward same-sex unions (Whitehead 2010). The indirect effect of gender, however, is still important and receives support in this study. The institution of marriage does not appear to have an influence on individuals' views of gay marriage or same-sex civil unions. Finally, religious tradition is not significantly associated with attribution beliefs, net of all other effects. This is contrary to recent studies where Evangelical Protestants were significantly different from other religious traditions regarding attribution beliefs (Haider-Markel and Joslyn 2008; Whitehead 2010). Most likely, the differences in political views, education, religious behaviors, and religious beliefs account for the differences across religious traditions.

Several limitations of the present study should be mentioned. First, while the fit statistics provide support that the hypothesized model tested in this analysis is a valid and good-fitting model, they do not in any sense "prove" that this model is the only correct model (Schumacker and Lomax 2010). Other model forms may fit the data as well. It is possible that for many individuals beliefs about the morality of homosexuality and same-sex unions are determined due to political and religious influences and these are primary in causal order to attribution beliefs. In this sense, individuals are either for or against gay marriage and to provide support for those beliefs, they view homosexuality as 
either innate or a choice. Most likely, the causal explanation identified in figure 1 and the other possible explanation outlined in this section both exist in reality. Both causal orders are present in qualitative research (see Moon 2004) and could realistically be applied quantitatively.

Second, the data utilized are cross-sectional. Even when utilizing path analysis, this precludes any possibility of determining causation. An ideal test of attribution theory would be able to incorporate changes in the attribution beliefs of individuals over time and confirm if those changes encouraged shifts in attitudes toward same-sex unions. This would also allow researchers to test the two possible causal orders discussed above. Finally, a number of studies point to the differences in attitudes toward gays versus lesbians and encourage delineating between the two when investigating public perception toward homosexuality (Herek 2002). This distinction is not possible utilizing the measures available in this study. Despite this limitation, Herek (2002) points out that in public discourse lesbians and gay men share a "common characteristic that makes them members of a distinct quasi-ethnic group with its own culture and political concerns" (Herek 2002:42). This suggests that while the questions employed in this analysis cannot distinguish between attitudes toward lesbians and gay men, they do tap into the broader set of attitudes maintained by a majority of the public. Conclusion

Using a recent, national survey of American adults and a more precise modeling technique, the present study provides support for attribution theory. More often than not, individuals construct opinions concerning the origin and controllability of a stigmatized status that significantly influences their attitudes toward persons in that group. It is important to recognize that attribution beliefs are indeed socially embedded. Political, religious, educational, and demographic influences shape attribution beliefs. So claims that only attribution beliefs make a difference are unwarranted. Changes in the political, religious, or educational composition of the United States could serve to shift attribution beliefs as well as attitudes toward same-sex unions. Nevertheless, future analyses of attitudes toward gays and lesbians or same-sex unions should include the attribution beliefs of 
individuals in addition to the standard collection of explanatory variables. Continued attempts to model the interrelationships utilizing structural equation or path modeling will hopefully continue as well. Such tests will confirm or challenge the results presented here and will provide necessary further evaluations of attribution theory.

Substantively, the findings from this study suggest that changes in attribution beliefs lead to changes in attitudes toward same-sex unions. Clearly, beliefs about same-sex unions and attribution explanations are closely tied and changes in one sphere will coincide with changes in the other. In fact, the association between attribution beliefs and same-sex union attitudes is greater than the total effects of political ideology and religious conservatism. Therefore, if a natural explanation for homosexuality is widely accepted, the entire issue of the legality of same-sex unions may be reframed. Individuals who already favor same-sex unions would now possess additional support for why gays and lesbians should be allowed to marry. Most likely, the discovery of a natural explanation for homosexuality would encourage a change in same-sex union attitudes among those individuals who occupy the middle ground in the debate. Individuals who are not strongly conservative either politically or religiously would be the first to amend their views. Due to the direct effects of political and religious conservatism on attitudes toward same-sex unions, a wider acceptance of a natural explanation of homosexuality would lead to the further marginalization of religiously and politically conservative individuals who oppose same-sex unions. The justification of their stance would have to be modified in such a way as to account for the uncontrollability of sexuality. It would no doubt become much more difficult to maintain such a stance in the midst of a culture that does not pinpoint responsibility for sexual orientation on individuals. In this way, attribution beliefs are persistently important to the overall discussion about homosexuality. Each side in the debate about equality for gays and lesbians is forced to reconcile their stance in response to the different possible attributions of homosexuality, whether those attributions provide direct support for their stance on gay rights or not. 
References

Asparouhov, T. and Bengt O. Muthén. 2010. "Weighted Least Squares Estimation with Missing Data." Retrieved from http://www.statmodel.com/download/GstrucMissingRevision.pdf.

Boysen, Guy A. and David L. Vogel. 2007. "Biased Assimilation and Attitude Polarization in Response to Learning About Biological Explanations of Homosexuality.” Sex Roles 57:755762.

Crocker, Jennifer, Beth Cornwell, and Brenda Major. 1993. "The Stigma of Overweight: Affective Consequences of Attributional Ambiguity.” Journal of Personality and Social Psychology 64:60-70.

Enders, C. K. 2010. Applied Missing Data Analysis. New York, NY: Guilford Press.

Fetner, Tina. 2008. How the Religious Right Shaped Lesbian and Gay Activism. Minneapolis, MN: University of Minnesota Press.

Griffin, William E. and Yaw Oheneba-Sakyi. 1993. "Sociodemographic and Political Correlates of University Students' Causal Attributions for Poverty.” Psychological Reports 73:795-800.

Haider-Markel, Donald P. and Mark R. Joslyn. 2008. "Beliefs About the Origins of Homosexuality and Support for Gay Rights: An Empirical Test of Attribution Theory.” Public Opinion Quarterly 72:291-310.

Heider, Fritz. 1944. "Social Perception and Phenomenal Causality.” Psychological Review 51:358-374.

Heider, Fritz. 1958. The Psychology of Interpersonal Relations. New York:Wiley.

Herek, Gregory M. 2002. "Gender Gaps in Public Opinion about Lesbians and Gay Men.” The Public Opinion Quarterly 66:40-66.

Herek, Gregory M., and John P. Capitanio. 1995. “Black Heterosexuals’ Attitudes Toward Lesbians and Gay Men in the United States.” Journal of Sex Research 32:95-105. 
Jöreskog, Karl G. 1993. “Testing Structural Equation Models.” In K. A. Bollen and J. Scott Long (eds.) Testing Structural Equation Models (294-316) Sage Publications, Inc: Newbury Park, CA.

Long, J. Scott. 1997. Regression Models for Categorical and Limited Dependent Variables. Thousand Oaks, CA: Sage Publications, Inc.

Moon, Dawne. 2004. God, Sex, and Politics: Homosexuality and Everyday Theologies. Chicago, IL: The University of Chicago Press.

Muthén, Linda K. and Bengt O. Muthén. 1998-2010. Mplus User's Guide. Sixth Edition. Los Angeles, CA: Muthén \& Muthén.

Olson, Laura R., Wendy Cadge, and James T. Harrison. 2006. "Religion and Public Opinion about Same-Sex Marriage.” Social Science Quarterly 87:340-60.

Putnam, Robert D. and David E. Campbell. 2010. American Grace: How Religion Divides and Unites Us. New York: NY: Simon and Schuster.

Sakalli, Nuray. 2002. "Application of the Attribution-Value Model of Prejudice to Homosexuality." The Journal of Social Psychology 142:264-71.

Schafer, J.L. 1997. Analysis of Incomplete Multivariate Data. London: Chapman \& Hall.

Schumacker, Randall E. and Richard G. Lomax. 2010. A Beginner's Guide to Structural Equation Modeling, $3^{\text {rd }}$ ed. New York: Routledge Academic.

Sherkat, Darren E., Kylan Mattias de Vries, and Stacia Creek. 2010. "Race, Religion, and Opposition to Same-Sex Marriage.” Social Science Quarterly 91(1): 80-98.

Sherkat, Darren E., Melissa Powell-Williams, Gregory Maddox, and Kylan Mattias de Vries. 2011. "Religion, Politics, and Support for Same-Sex Marriage in the United States, 1988-2008." Social Science Research 40: 167-180. 
Steensland, Brian, Jerry Z. Park, Mark D. Regnerus, Lynn D. Robinson, W. Bradford Wilcox, and Robert D. Woodberry. 2000. "The Measure of American Religion: Toward Improving the State of the Art." Social Forces, 79(1):291-318.

Weiner, Bernard. 1979. “A Theory of Motivation for Some Classroom Experience.” Journal of Educational Psychology 71:3-25.

Weiner, Bernard. 1985. “An Attribution Theory of Achievement, Motivation, and Emotion.” Psychological Review 92:548-573.

Weiner, Bernard, Raymond Perry, and Jamie Magnusson. 1988. “An Attributional Analysis of Reactions to Stigmas.” Journal of Personality and Social Psychology 55:738-748.

Whitehead, Andrew L. 2010. 'Sacred Rites and Civil Rights: Religion’s Effect on Attitudes toward Same-Sex Unions and the Perceived Cause of Homosexuality.” Social Science Quarterly 91:63-78.

Whitehead, Andrew L. and Joseph O. Baker. "Homosexuality, Religion, and Science: Moral Authority and the Persistence of Negative Attitudes." Sociological Inquiry 82(4): 487-509.

Wood, Peter B. and John P. Bartkowski. 2004. "Attribution Style and Public Policy Attitudes toward Gay Rights.” Social Science Quarterly 85:58-74.

Zucker, Gail S. and Bernard Weiner. 1993. "Conservatism and Perceptions of Poverty: An Attributional Analysis.” Journal of Applied Social Psychology 23:925-943. 
Figure 1: Hypothesized Path Model for Selected Covariates

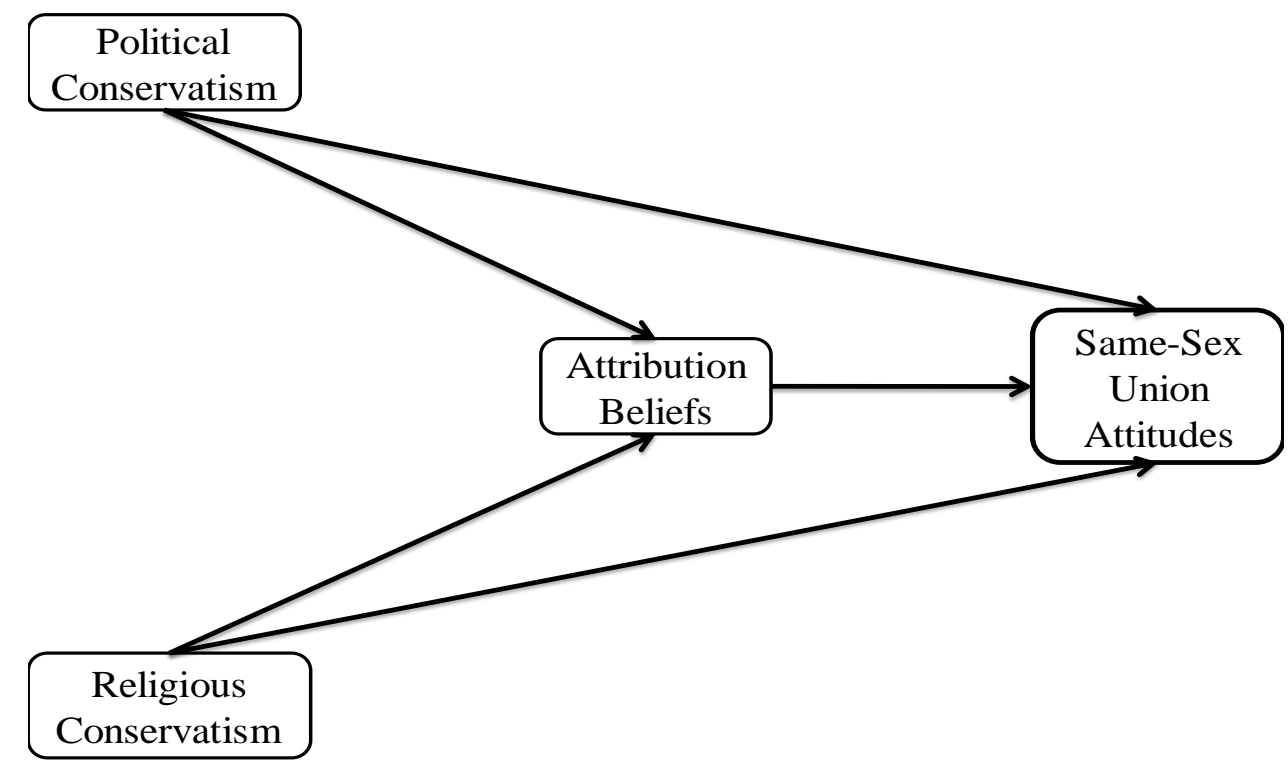


Figure 2: Parameter Estimates of Path Model for Choice Attribution and Support of Same-Sex Marriage

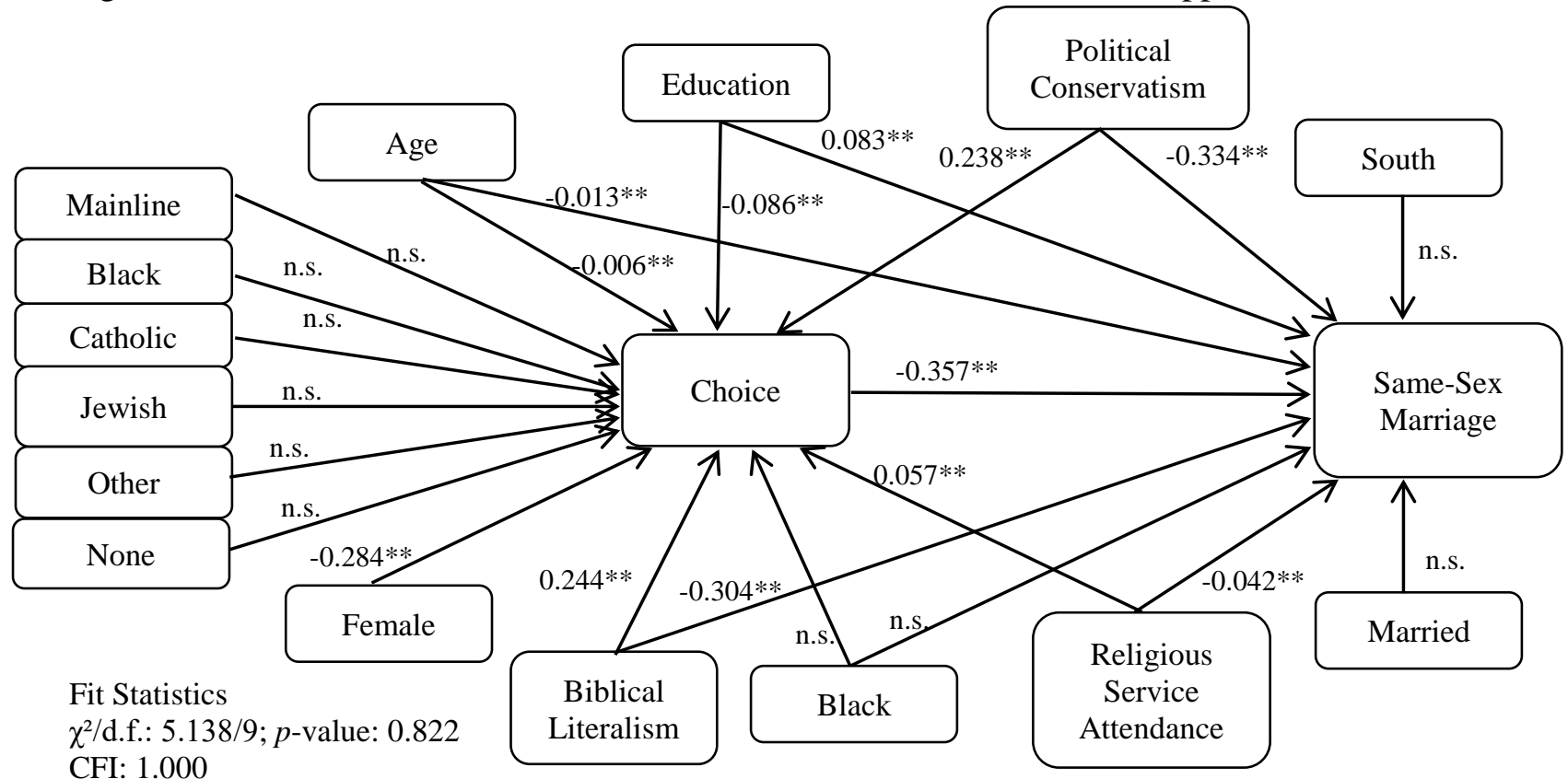

CFI: 1.000

TLI: 1.023

RMSEA: 0.000

Source: BRS (2010); N=1,714

n.s. $=$ non-significant; $* \mathrm{p}<.05 ; * * \mathrm{p}<.01$ 
Figure 3: Parameter Estimates of Path Model for Born Attribution and Support of Same-Sex Marriage

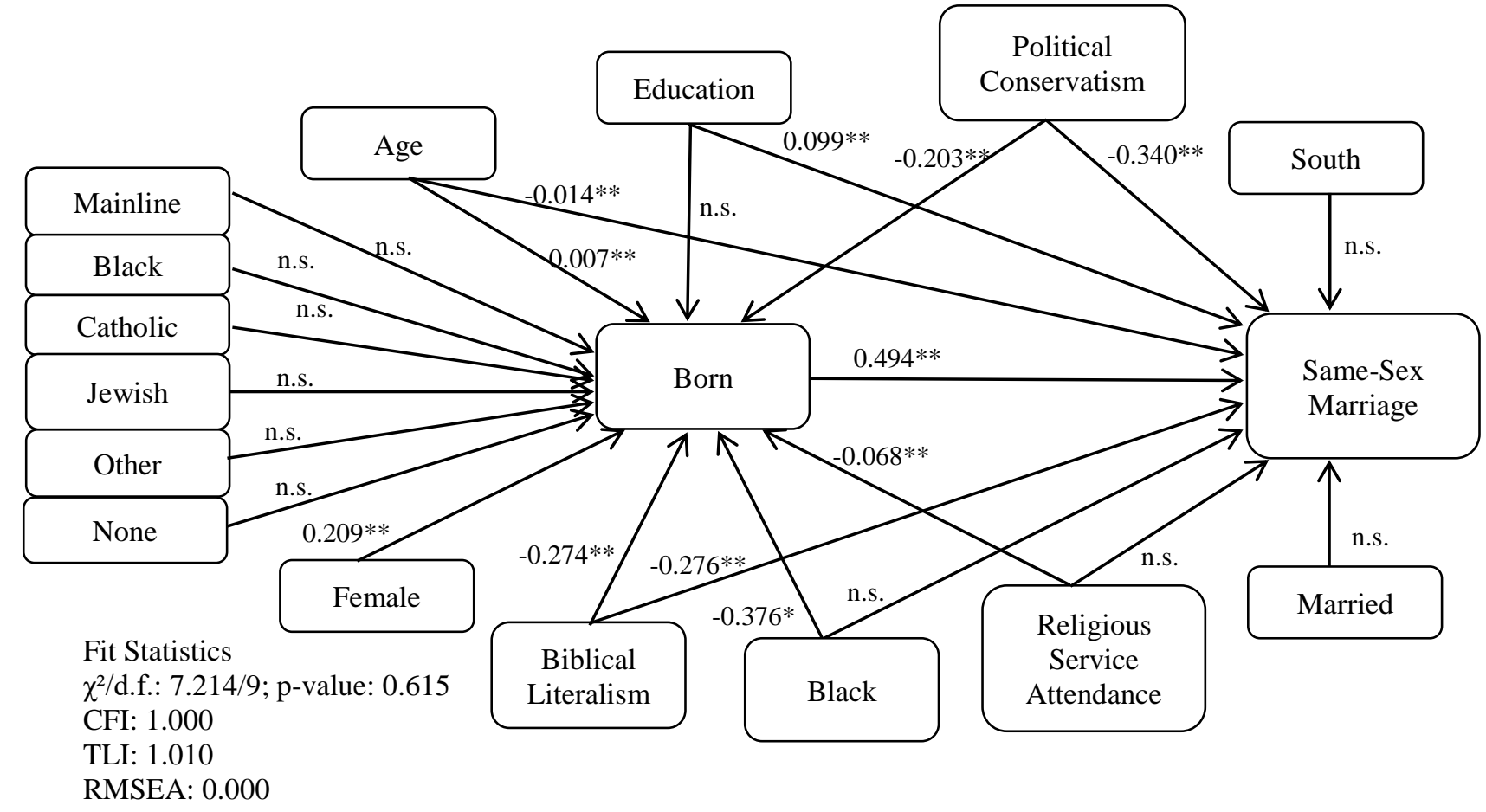

Source: BRS (2010); $\mathrm{N}=1,714$

n.s. $=$ non-significant; $* \mathrm{p}<.05 ; * * \mathrm{p}<.01$ 
Figure 4: Parameter Estimates of Path Model for Choice Attribution and Support of Same-Sex Civil Unions

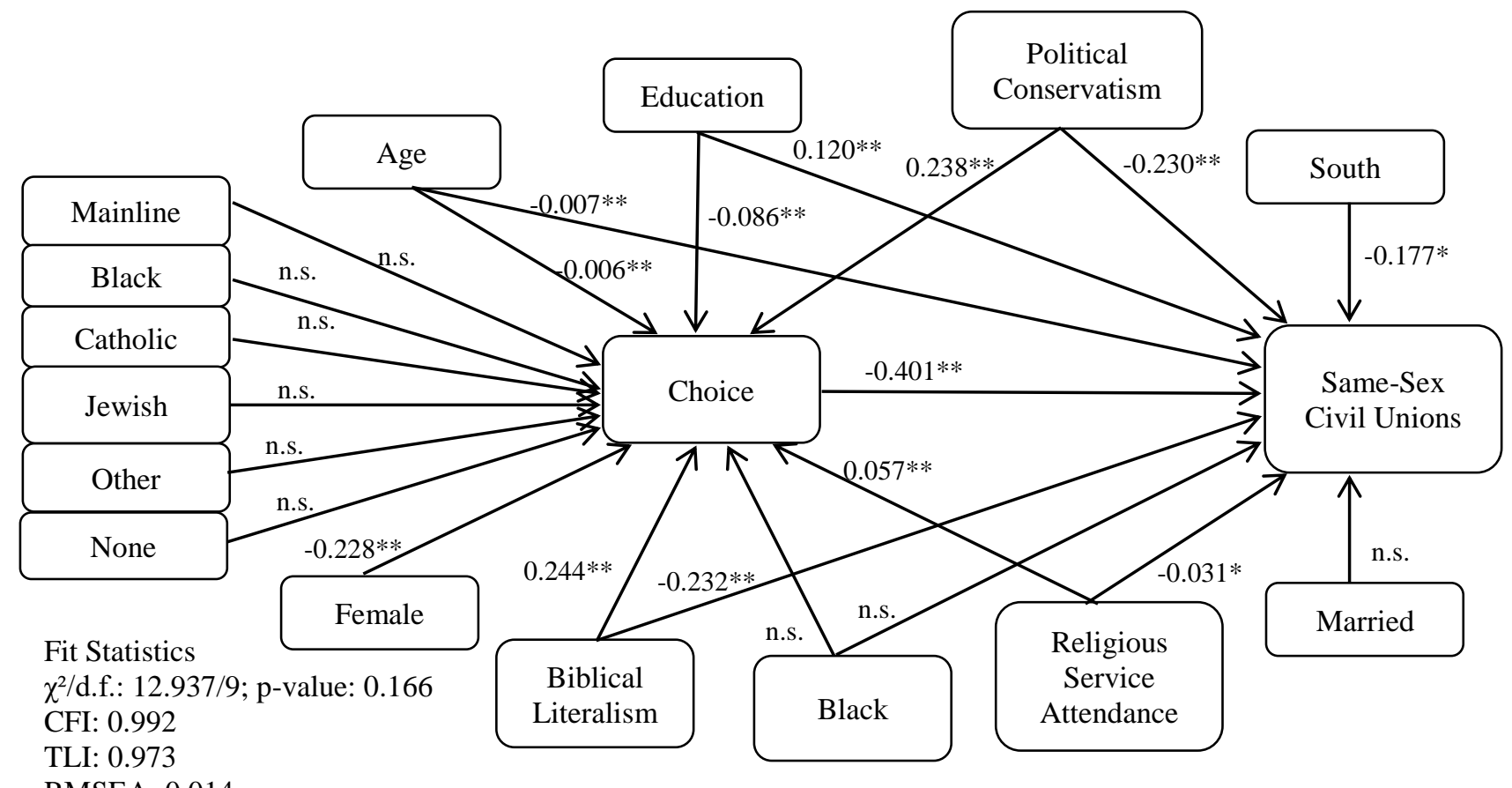

RMSEA: 0.014

Source: BRS (2010); $\mathrm{N}=1,714$

n.s. $=$ non-significant; $* \mathrm{p}<.05 ; * * \mathrm{p}<.01$ 
Figure 5: Parameter Estimates of Path Model for Born Attribution and Support of Same-Sex Civil Unions

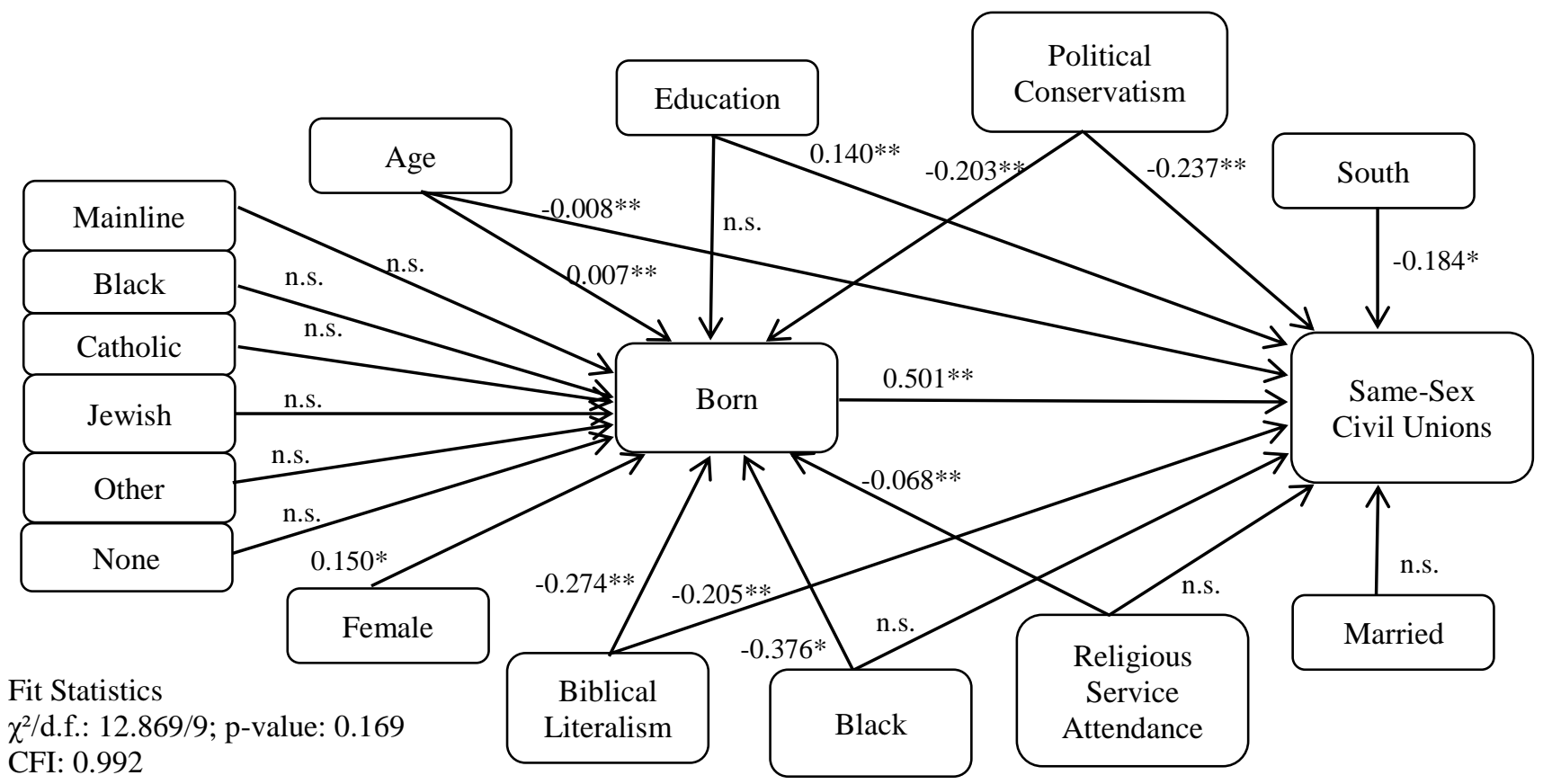

TLI: 0.974

RMSEA: 0.014

Source: BRS (2010); $\mathrm{N}=1,714$

n.s. $=$ non-significant; $* \mathrm{p}<.05 ; * * \mathrm{p}<.01$ 
Table 1: Total, Direct, and Indirect Standardized Effects

\begin{tabular}{lllllll}
\hline Marriage & Total & Direct & Indirect & Total & Direct & Indirect \\
\hline Born & --- & --- & & 0.727 & 0.727 & \\
Choice & -0.568 & -0.568 & --- & --- & \\
$\begin{array}{l}\text { Political } \\
\text { Conservatism }\end{array}$ & -0.487 & -0.352 & -0.135 & -0.549 & -0.344 & -0.205 \\
Biblical Literalism & -0.335 & -0.211 & -0.124 & -0.365 & -0.183 & -0.182 \\
Civil Unions & & & & & & \\
\hline $\begin{array}{l}\text { Born } \\
\text { Choice }\end{array}$ & --- & --- & & 0.814 & 0.814 & \\
Political & -0.694 & -0.694 & & --- & --- & \\
Conservatism & -0.490 & -0.265 & -0.225 & -0.495 & -0.265 & -0.230 \\
Biblical Literalism & -0.328 & -0.176 & -0.152 & -0.355 & -0.151 & -0.204 \\
\hline
\end{tabular}

